\title{
Política de vivienda y política impositiva: incentivos al ahorro e incentivos a la inversión*
}

\author{
Miguel-Ángel López García \\ Universidad Autónoma de Barcelona
}

\section{Resumen}

El propósito de este trabajo es discutir algunos aspectos de la relación entre política de vivienda y política impositiva. Para ello se exploran las consecuencias de la distinción entre los «incentivos al ahorro» (políticas universales que no distinguen entre las viviendas preexistentes y las de nueva creación) y los «incentivos a la inversión» (políticas selectivas dirigidas específicamente a las viviendas nuevas). Se afirma que el ordenamiento fiscal en España ha venido sido equivalente a la conjunción de un incentivo al ahorro positivo y un incentivo a la inversión negativo. Tras la eliminación de las desgravaciones por adquisición de vivienda, la situación puede caracterizarse como un incentivo al ahorro negativo combinado con un incentivo a la inversión también negativo.

Palabras clave: mercado de vivienda, política de vivienda, política impositiva.

Clasificación JEL: E62, H22, H24, R21, R31.

\begin{abstract}
This paper focuses on the relationship between housing policy and tax policy. To this end, the consequences of the distinction between the so-called «savings incentives» (universal policies that do not distinguish between pre-existing and newly-produced housing) and «investment incentives» (selective policies specifically addressed to newly-produced housing units) are explored. We show that the legislation in Spain gave rise to a positive savings incentive coupled with a negative investment incentive. After the abrogation of tax subsidies to owner-occupied housing, the situation can be characterized as a negative savings incentive combined with a negative investment incentive.
\end{abstract}

Keywords: housing market, housing policy, tax policy.

JEL classification: E62, H22, H24, R21, R31.

\section{Introducción}

Si este trabajo hubiera sido escrito hace bien pocos años, probablemente habría hecho referencia en el primer párrafo al «problema de la vivienda» como uno de aquellos que suscitan más preocupación en la sociedad española. Bien es cierto

* El presente trabajo es consecuencia de una ayuda a la investigación sobre vivienda y fiscalidad concedida por el Instituto de Estudios Fiscales, cuyo soporte económico se señala con agradecimiento. También ha recibido el apoyo institucional del Proyecto ECO2012-37572 del Ministerio de Economía y Competitividad, y del Proyecto 2014SGR327 y la Xarxa de Referència en Economia i Polítiques Públiques de la Generalitat de Catalunya. 
que en tiempos recientes muchas otras problemáticas han venido a engrosar la lista de incidencias que generan desazón entre nuestros conciudadanos. Pero parece difícil discutir que las consecuencias de aquellos, ahora aparentemente tan lejanos, booms inmobiliarios se seguirán sintiendo durante largos años y en una variedad de fenómenos, hasta el punto de proporcionar toda una agenda de investigación a los científicos sociales.

El mercado de la vivienda en España ha presentado y presenta características peculiares. En primer lugar, la forma de tenencia en alquiler ha sido, y continúa siendo, muy pequeña cuando se realiza la comparación con otros países europeos, hasta el punto que España ha sido en ocasiones caracterizada como «un país de propietarios». En segundo lugar, la construcción constituye un sector clave de la economía española, y con ella todos aquellos sectores relacionados de una u otra forma con la vivienda. Esta importancia quedó de manifiesto a lo largo del ciclo expansivo que finalizó abruptamente en 2007. En el periodo 1997-2007, la demanda de vivienda experimentó un gran aumento y la respuesta de la oferta de vivienda de nueva creación fue notable, dando como resultado tasas anuales de crecimiento de los precios inmobiliarios del 8 por 100. No resulta sorprendente que ese boom llevara a instituciones internacionales como la OCDE, el FMI o la Comisión Europea a llamar la atención sobre estos desequilibrios.

Las desgravaciones fiscales a la vivienda habitual en propiedad constituyen probablemente una de las preferencias fiscales con mayor apoyo ciudadano. Prueba de ello es que el Impuesto sobre la Renta de las Personas Físicas, desde su introducción hasta fechas bien recientes, ha comportado unos generosos subsidios a la vivienda ocupada por su propietario. Sin embargo, un dedo acusador las ha venido señalando de forma recurrente, tildándolas de contribuir a las alzas del precio de la vivienda e incluso de acabar en los bolsillos de los constructores-promotores a través de procesos de capitalización no siempre bien explicados. Sea como fuere, desde enero de 2013 ya no es posible desgravar en la adquisición de viviendas, si bien aquellos contribuyentes que las adquirieron antes de esa fecha pueden continuar invocando los subsidios fiscales. Adicionalmente, y también desde enero de 2013, el impuesto sobre el valor añadido aplicable a las transacciones de viviendas de nueva construcción, tras bajar del 8 al 4 por 100 y mantenerse así de forma efímera por poco más de un año, fue incrementado hasta el 10 por 100.

El propósito de este trabajo es discutir algunos aspectos de la relación entre política de vivienda y política impositiva, y en particular cómo la segunda puede constituir un instrumento al servicio de la primera. Para ello se analiza el papel que pueden jugar la variedad de subsidios e impuestos ligados a la vivienda, habitual y en propiedad. En aras de la simplicidad, no se tendrá en cuenta la decisión respecto a la forma de tenencia propiedad-alquiler, como tampoco las segundas residencias u otros motivos para mantener viviendas en las carteras privadas. Aunque este supuesto pueda ser tildado como restrictivo, su propósito no es otro que poder ver en puridad los efectos de las diversas políticas discutidas, sin que éstos se vean desdibujados por otras circunstancias, sin duda relevantes, pero ajenas a las consecuencias de aquéllas. 
Después de todo, invocando una de las frases favoritas de Samuelson, que una cosa no esté en el polo norte, no la coloca de forma automática en el polo sur.

La estructura del trabajo es como sigue. La sección 2 presenta el marco para el análisis, constituido por un modelo agregado de la vivienda como activo. Una vez especificado el comportamiento de los consumidores-propietarios y el del sector de la construcción residencial, se analiza la determinación del precio de la vivienda (preexistente, en contraposición a la nueva) y del stock de capital residencial. La sección 3 realiza una primera aproximación a los efectos, tanto a corto como a largo plazo, resultantes de modificar los parámetros impositivos. Para ello se distingue entre aquellos subsidios (incorporados a la imposición sobre la renta personal) e impuestos (que gravan las transacciones de vivienda) cuyos efectos se canalizan a través de las decisiones de consumo-adquisición de vivienda o a través de las decisiones relacionadas con la inversión residencial. En la sección 4 se introduce la crucial distinción entre los «incentivos al ahorro» (políticas universales que no distinguen entre las viviendas preexistentes y las de nueva creación) y los «incentivos a la inversión» (políticas selectivas dirigidas específicamente a las viviendas nuevas), y se discuten los efectos de ambas políticas sobre el precio real de la vivienda preexistente y sobre el stock de capital residencial. La sección 5 avanza una evaluación de la política impositiva dirigida a la vivienda en propiedad en España. Se argumenta que hasta fechas recientes ha comportado un incentivo al ahorro positivo y un incentivo a la inversión negativo, y que tras la supresión de las desgravaciones fiscales la situación puede caracterizarse como un incentivo al ahorro negativo combinado con un incentivo a la inversión también negativo. La sección 6 concluye con algunos comentarios finales. El Apéndice resume algunas cuestiones técnicas referidas a la dinámica del modelo y proporciona algunas referencias bibliográficas.

\section{Una modelización del mercado de la vivienda}

El modelo de vivienda agregado que proporciona el marco para el análisis se centra en la forma de tenencia de aquélla en propiedad. Por un lado, tiene en cuenta las decisiones de consumo de servicios-stock de vivienda por parte de los consumidores-propietarios. Por el otro, especifica el comportamiento de la construcción residencial, destacando el papel del suelo (y por ende de su precio) en tanto que factor de producción fundamental para la construcción de viviendas nuevas. La determinación del precio del activo vivienda y del stock de capital residencial se cierra con un mecanismo de formación de expectativas por parte de los agentes respecto a la evolución futura de los precios reales de la vivienda.

\subsection{El equilibrio en el mercado de stock de vivienda}

Comenzando por el análisis del flujo de servicios de vivienda, $H S$, generados y consumidos por el propietario de un stock de vivienda $H$, la demanda de aquéllos, 
$H S^{D}$, dependerá del alquiler nocional que un consumidor-propietario «se paga a sí mismo», $R$, de la medida de la renta de las economías domésticas relevante para sus decisiones de vivienda, $Y$ (su renta permanente o de ciclo vital), así como del número de hogares, $N$ (y, en general, de la estructura demográfica de la población). Formalmente, $H S^{D}=f(R, Y, N)$. La oferta de servicios de vivienda, $H S^{S}$, puede resumirse en la función de producción $H S^{S}=g(H)$, dado que el consumidor es a la vez productor de los servicios generados por el stock $H$ cuya propiedad ostenta. Por tanto, la condición de equilibrio en el mercado de servicios de vivienda, $f(R, Y, N)=g(H)$, caracteriza de forma implícita la demanda de stock de vivienda en propiedad en función del alquiler nocional, de la renta permanente o de ciclo vital y de las variables sociodemográficas. Esta demanda puede escribirse en forma inversa como $R=R(H, Y, N)$, y proporciona la valoración marginal asociada a una cantidad dada de stock de vivienda para valores dados de las variables consideradas como exógenas, $Y$ y $N$.

Los consumidores-propietarios adquirirán aquella cantidad de stock de vivienda para la cual la valoración marginal de los servicios que genera aquél es igual a su coste marginal. En el presente contexto este último está asociado a la noción de coste de uso del capital residencial. Este coste de uso incorporará los intereses de los capitales ajenos solicitados (teniendo en cuenta la posible deducibilidad de los mismos en el impuesto sobre la renta de las personas físicas -IRPF- a cierto porcentaje $b$ ), el coste de oportunidad de los fondos propios utilizados en la adquisición (neto de los impuestos sobre la renta a tipo $\tau_{\text {IRPF }}$ que en su caso se hubieran satisfecho), la depreciación y el mantenimiento de la unidad de vivienda, los pagos del impuesto sobre bienes inmuebles (IBI), así como el coste negativo derivado de la apreciación nominal de la vivienda. El precio al productor (es decir, sin tener en cuenta los impuestos o subsidios ligados a la transacción) de una unidad de stock de vivienda en términos nominales no es sino el producto del nivel general de precios, $p$ (que en lo que sigue, y sin pérdida de generalidad, se normaliza igual a la unidad), y su precio real, $P_{H}$. En consecuencia, la variación esperada del precio nominal de la vivienda puede ser debida a la inflación general, a tasa $\pi$, o al aumento esperado del precio real de la vivienda, $\dot{P}_{H}^{e}$ (donde el punto encima de una variable denota la derivada temporal).

El precio al consumidor (es decir, el relevante para el comprador) de las viviendas existentes es el resultado de aplicar al precio al productor los impuestos que gravan las transacciones de las viviendas usadas, es decir, el impuesto sobre transmisiones patrimoniales (ITP) a tipo $\tau_{\text {ITP }}$, así como los posibles subsidios en el IRPF por adquisición de vivienda, resumidos en cierto porcentaje $c$. Esto hace que el precio al consumidor de una vivienda usada acabe siendo $P_{H}\left(1+\tau_{I T P}\right)(1-c)$. En la situación previa a la reciente eliminación de las desgravaciones por vivienda el porcentaje de desgravación aplicable a los intereses y al principal era el mismo, es decir, $b=c$. Pero debe observarse que no hay razón alguna para esto deba ser así, como en efecto sucedió en periodos pasados (hasta la reforma del IRPF de 1998), en que los intereses eran deducibles de la base del impuesto (y así, al tipo marginal del contribuyente en cuestión) y los pagos de principal de la cuota (dando lugar así a un crédito fiscal). 
En consecuencia, denominando $\omega$ al coste de uso por unidad de capital residencial, la condición de equilibrio en el mercado de stock de vivienda puede escribirse como $R(H, Y, N)=\omega P_{H}$, donde:

$$
\begin{array}{r}
\omega=\left\{\left[r i_{p}(1-b)+(1-r) i_{o}\left(1-\tau_{I R P F}\right)\right]+d+m+k \tau_{I B I}-\left(1-\tau_{\Delta P A T}\right)\left(\pi+\frac{\dot{P}_{H}^{e}}{P_{H}}\right)\right\} \\
\left(1+\tau_{I T P}\right)(1-c)
\end{array}
$$

En [1], $i_{p}$ es el tipo de interés nominal de los préstamos para la adquisición de vivienda, $i_{o}$ es el coste de oportunidad de los fondos propios y $r$ la relación préstamo-valor. En consecuencia, los términos $r i_{p}(1-b)$ y $(1-r) i_{o}\left(1-\tau_{\text {IRPF }}\right)$ capturan respectivamente la deducibilidad en la cuota del IRPF de los intereses de los capitales ajenos utilizados para la compra de una vivienda y la consideración del tratamiento fiscal del coste de oportunidad de los fondos propios. Estos, junto con la depreciación y el mantenimiento, a tasas $d$ y $m$, respectivamente, constituyen costes asociados a la propiedad de vivienda. El paréntesis $\left(1+\tau_{\text {ITP }}\right)(1-c)$ recoge el hecho de que las transacciones de una vivienda ya construida cuyo precio real al productor es $P_{H}$ están sujetas al ITP, así como la posibilidad de que, en su caso, el comprador pueda acogerse a un porcentaje $c$ de desgravación por adquisición de vivienda en el IRPF. Por su parte, $k \tau_{I B I}$ es el producto del tipo del IBI y el porcentaje valor catastral/valor de mercado, y puede considerarse el gravamen efectivo del impuesto sobre la propiedad. Estos pagos por IBI no son deducibles ni de la base ni de la cuota del IRPF (y el hecho de que $k \tau_{I B I}$ esté afectado por $\left(1+\tau_{I T P}\right)(1-c)$ es una mera consecuencia de haber tomado en la definición de $k$ el precio al consumidor como valor de mercado). Finalmente, $\tau_{\triangle P A T}$ denota el gravamen efectivo sobre las ganancias de capital vivienda, de suerte que el «coste negativo» asociado a la tasa de variación del precio nominal de la vivienda, $\left(\pi+\frac{\dot{P}_{H}^{e}}{P_{H}}\right)$, se afectado por el término impositivo $\left(1-\tau_{\triangle P A T}\right)$.

En cuanto al mecanismo de formación de expectativas, dos casos polares emergen de forma natural en el presente contexto, según los agentes económicos tengan expectativas estáticas o expectativas racionales. El caso en que los individuos tienen expectativas estáticas caracteriza una situación en que los agentes no esperan variación alguna en el valor real de sus viviendas, y equivale a hacer $\dot{P}_{H}^{e}=0$ en [1]. Por el contrario, el caso en que los agentes tienen expectativas racionales, lo que en el presente marco determinista equivale al supuesto de previsión perfecta, es tal que $\dot{P}_{H}^{e}=\dot{P}_{H}$. Los individuos ahora, por así decirlo, «conocen el modelo» y «aciertan» el cambio en el precio real de sus viviendas. Estas dos hipótesis comportan visiones antitéticas respecto al grado de sofisticación de los agentes. Mientras en el primer caso los individuos son «lerdos-lerdos», en el segundo son «listos-listos». Aunque no es fácil encontrar alternativas a unas expectativas racionales en los modelos teóricos, puede valer la pena comparar los resultados con los que surgen en la situación en que 
los individuos mantienen unas expectativas estáticas. Sea como fuere, y si bien las trayectorias dinámicas difieren, los equilibrios a largo plazo a que convergen éstas son exactamente los mismos.

Con unas expectativas racionales, haciendo $\dot{P}_{H}^{e}=\dot{P}_{H}$ en [1], la condición de equilibrio en el mercado de la vivienda como activo, $R=\omega P_{H}$, determina la variación del precio real de la vivienda ya construida en función del propio nivel de su precio, del stock de viviendas existentes, y de los valores de las variables exógenas, de las que a nuestros efectos destacaremos los parámetros fiscales $b, c, \tau_{I T P}$ y $\tau_{\triangle P A T}$ :

$$
\begin{aligned}
& \dot{P}_{H}=\frac{\left[r i_{p}(1-b)+(1-r) i_{o}\left(1-\tau_{\text {IRPF }}\right)\right]-\left(1-\tau_{\triangle P A T}\right) \pi+d+m+k \tau_{I B I}}{\left(1-\tau_{\triangle P A T}\right)} P_{H}- \\
&-\frac{R(H, Y, N)}{\left(1+\tau_{I T P}\right)(1-c)\left(1-\tau_{\triangle P A T}\right)}
\end{aligned}
$$

Si, alternativamente, las expectativas son estáticas, la condición de equilibrio en el mercado de la vivienda como activo es [2] con $\dot{P}_{H}=0$.

Es importante hacer notar que esta forma de modelizar el comportamiento de los consumidores-adquirentes de vivienda como una condición que iguala la valoración y el coste marginal del stock de vivienda es equivalente a postular una condición de arbitraje entre el rendimiento del activo vivienda y el rendimiento de los activos alternativos en los que los individuos pueden materializar su riqueza. El valor neto de los servicios de vivienda derivados de una unidad de stock de capital residencial será el valor bruto de los mismos (es decir, $R$ ), menos los costes asociados a la depreciación, el mantenimiento y los diversos impuestos implicados. El precio de una unidad de stock será entonces igual al valor presente descontado de su flujo de servicios futuros en términos netos.

\subsection{El comportamiento de la construcción residencial}

En cuanto a la construcción de viviendas, la inversión residencial bruta, $I$, se verá afectada positivamente por el precio de las viviendas nuevas, $P_{H N}$, y negativamente por los precios de los factores productivos requeridos para su producción (suelo, trabajo y materiales de construcción), que en aras de la simplicidad podemos resumir en el precio real del suelo, $P_{L}$ (recuérdese que el nivel general de precios $p$ se ha normalizado a la unidad). Esta relación, que no es sino la curva de oferta de viviendas nuevas para un precio del suelo dado, puede escribirse como $I=h\left(P_{H N}, P_{L}\right)$. Suponer que el precio del suelo es exógeno no parece, sin embargo, un supuesto demasiado plausible. Entre los candidatos a afectar al precio del suelo, además de las ordenaciones de zonificación (que se toman como dadas), tanto la propia inversión residencial bruta $I$ como el stock de vivienda $H$ emergen como candidatos a constituir algunos de los condicionantes, de forma que $P_{L}=k(I, H)$. La primera porque proporciona una 
medida inmediata de la «temperatura» del sector de la construcción, y la segunda por un argumento de corte Ricardiano ligado a la literatura sobre localización residencial que ha sido avanzado en algunas ocasiones. Sustituyendo esta última relación en la inversión residencial bruta, ésta dependerá ahora del precio de las viviendas nuevas y del propio stock, $I=I\left(P_{H N}, H\right)$. Nótese que en esta curva de oferta de viviendas nuevas el precio del suelo es una variable endógena, y no es difícil mostrar esta curva de oferta es más inelástica que su contrapartida con un precio del suelo exógeno, $I=h\left(P_{H N}, P_{L}\right)$.

Vale la pena también señalar que la forma de modelizar el precio del suelo esbozada más arriba permite obtener éste en función de los valores del precio de la vivienda nueva y el stock de capital residencial. En otras palabras, resulta posible relacionar de forma directa el precio del suelo y el precio de la vivienda, en el sentido de que el primero se ve afectado por el segundo, una relación que, por cierto, ha sido señalada repetidamente como característica de la situación en nuestro país. En efecto, sustituyendo $I=I\left(P_{H N}, H\right)$ en la relación postulada para el precio del suelo, resulta, con una notacion obvia, $P_{L}=m\left(P_{H N}, H\right)$, de suerte que cuanto mayor sea, todo lo demás constante, el precio de las viviendas nuevas (y como veremos inmediatamente, por arbitraje, también el de las de segunda mano) mayor será también el precio del suelo.

Restando de la inversión residencial bruta la depreciación a tasa $d$ del stock existente, resultará la inversión neta, es decir, la variación temporal del stock de capital residencial, $\dot{H}$. Esta dependerá del precio $P_{H N}$ de las viviendas de nueva construcción y del stock, esto último no solo a través de la depreciación sino también del efecto del stock sobre el precio del suelo:

$$
\dot{H}=I\left(P_{H N}, H\right)-d H
$$

A la luz de la discusión anterior la pregunta que surge de forma inmediata es cuál es la relación que puede haber entre los precios de las viviendas usadas y nuevas en los párrafos anteriores, y por qué no se han presentado como iguales. La respuesta debe encontrarse en el hecho de que, en presencia de impuestos y/o subsidios diferentes sobre ambos tipos de vivienda, aquellos precios serán sencillamente diferentes. Dado que el stock de vivienda se está considerando como algo homogéneo, con independencia de si se trata de viviendas nuevas o usadas, y puesto que unidades de vivienda (esencialmente) iguales han de tener el mismo precio al consumidor, existirá una condición de arbitraje entre aquéllos que relacionará, a su vez, los precios al productor de las viviendas usadas y de las viviendas nuevas.

Por definición, esa condición de arbitraje tomará en consideración los impuestos que gravan sus transacciones y los subsidios fiscales que resultan aplicables en la adquisición de cada una de esas modalidades. En cuanto a los impuestos, las nuevas están sujetas al tipo reducido del impuesto sobre el valor añadido (IVA) y por el impuesto sobre actos jurídicos documentados (IAJD) con ocasión de la inscripción registral, gravámenes que podemos resumir en cierto tipo impositivo $\tau_{\text {IVAD }}$. Y como 
ya se ha señalado, las usadas lo están al impuesto sobre transmisiones patrimoniales a tipo $\tau_{I T P}$. Por su parte, ya se ha observado que si bien los subsidios fiscales aplicables en la adquisición (o, si se prefiere, por pago de principal como concepto diferenciado de las deducciones fiscales por pagos de intereses de capitales ajenos) fueron en tiempos recientes iguales para las viviendas nuevas y usadas, nada obliga a que deba ser siempre así (tal y como acaeció en nuestro país en el periodo 198587). Resumiendo esas desgravaciones en los tipos efectivos $s$ y $c$ para las viviendas nuevas y usadas respectivamente, la condición de arbitraje descrita en el párrafo anterior deviene:

$$
P_{H N}\left(1+\tau_{\text {IVAD }}\right)(1-s)=P_{H}\left(1+\tau_{I T P}\right)(1-c)
$$

Claramente, si $c$ difiere de $s$ y/o $\tau_{I T P}$ lo hace de $\tau_{I V A D}, P_{H}$ diferirá de $P_{H N}$. Cuando $c=s$, es decir, cuando los subsidios por adquisición de vivienda no distinguen entre una unidad nueva o preexistente, [4] se reduce a $P_{H N}\left(1+\tau_{I V A D}\right)=P_{H}\left(1+\tau_{I T P}\right)$. Es importante señalar que incluso en este caso, si los tipos impositivos $\tau_{\text {ITP }}$ y $\tau_{\text {IVAD }}$ que gravan las transacciones de ambas modalidades son diferentes, también lo serán $P_{H}$ y $P_{H N}$. Sustituyendo [4] en [3] resulta:

$$
\dot{H}=I\left(P_{H} \frac{\left(1+\tau_{I T P}\right)(1-c)}{\left(1+\tau_{\text {IVAD }}\right)(1-s)}, H\right)-d H
$$

Nótese que algunos de los parámetros fiscales que aparecen en [5], en concreto los asociados a las unidades de vivienda de nueva producción, $\tau_{\text {IVAD }}$ y $s$, no están presentes en [2]. Obsérvese también que cuando las viviendas nuevas y usadas están sujetas al mismo tratamiento impositivo y de subsidio, es decir, cuando $\tau_{I T P}=\tau_{I V A D} \mathrm{y}$ $c=s$, los términos impositivos en [5] se anulan, y resulta la relación que regiría en ausencia de ambos, es decir, $\dot{H}=I\left(P_{H}, H\right.$ ) (que, nótese, difiere de [3] en tanto que el precio relevante ahora es el de las viviendas usadas, sin más).

\subsection{La determinación del precio de la vivienda y el stock de capital residencial}

Con unas expectativas racionales, las expresiones [2] y [5] caracterizan las trayectorias temporales del precio de las viviendas existentes y del stock de capital residencial para valores concretos de los diversos parámetros implicados, tanto fiscales como no fiscales, así como para ciertas condiciones iniciales de $P_{H}$ y $H$. En consecuencia, los estados estacionarios pueden interpretarse como equilibrios a largo plazo. Estos últimos están constituidos por las situaciones en que tanto el precio real de la vivienda como el stock de capital residencial no varían, de manera que no existen ni ganancias ni pérdidas reales de capital vivienda y la inversión residencial neta es nula. $\mathrm{Si}$, por el contrario, las expectativas son estáticas, la condición de equilibrio en el mercado de la vivienda como activo permite escribir $P_{H}$ como función de $H$, 
y sustituyendo en [5], puede obtenerse la evolución temporal del stock de vivienda dada una condición inicial y el conjunto de parámetros fiscales.

En el Gráfico 1 , la línea $\dot{P}_{H}=0$ representa las combinaciones de precio y stock compatibles con unas ganancias reales de capital vivienda nulas (de suerte que los precios nominales crecen a la tasa de inflación general). Su forma decreciente es consecuencia de que cuanto mayor sea el stock (y, por ende, menor la valoración marginal que de él tienen los individuos), menor deberá ser el precio real de la vivienda que hace que los consumidores-propietarios deseen mantener aquel stock. Por su parte, la línea $\dot{H}=0$ es el lugar geométrico de las combinaciones de precios y stock tales que la inversión residencial neta es nula, es decir, tales la inversión bruta (de reposición) es exactamente igual a la depreciación del stock existente. Su forma creciente se sigue del hecho de que un mayor stock comportará una mayor depreciación, y ésta requerirá, a su vez, una mayor inversión de reposición para mantener invariado el stock, lo cual solo es posible con precios de la vivienda mayores. En cualquier caso, como se acaba de observar, los lugares geométricos $\dot{P}_{H}=0$ y $\dot{H}=0$ no son, ni se pueden interpretar como, curvas de oferta y demanda.

\section{GRÁFICO 1 \\ CONDICIONES INICIALES Y CONSECUCIÓN DEL EQUILIBRIO A \\ LARGO PLAZO DEL PRECIO REAL AL PRODUCTOR DE LAS VIVIENDAS \\ PREEXISTENTES Y DEL STOCK DE CAPITAL RESIDENCIAL}

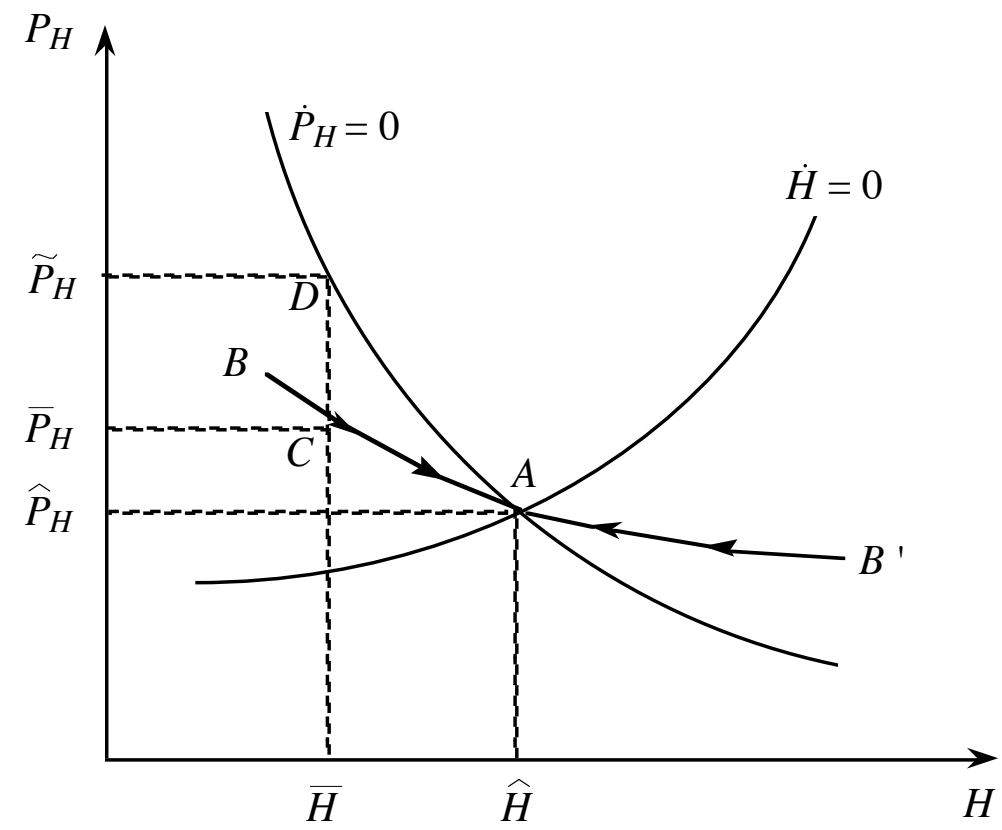


El equilibrio estacionario vendrá dado por el punto $A$ en que se cortan ambas líneas. En cuanto a la dinámica, la hipótesis de que las expectativas son racionales implica que la consecución de los valores $\hat{P}_{H}$ y $\hat{H}$ debe tener lugar a lo largo del lugar geométrico $B B^{\prime}$. Cualquier condición inicial que no se halle sobre $B B^{\prime}$ comportará el alejamiento del equilibrio a largo plazo. Así, dada la condición inicial $\bar{H}$, el precio del activo vivienda debe ajustarse hasta el nivel $\bar{P}_{H}$ para colocarse sobre el punto $C$ de la línea $B B^{\prime}$, y converger así hacia el estado estacionario $\left(\hat{P}_{H}, \hat{H}\right)$. Por el contrario, con unas expectativas estáticas los agentes no esperan cambios en el precio real de la vivienda, es decir, conjeturan que en todo instante se cumplirá que $\dot{P}_{H}=0$. Dada la condición inicial $\bar{H}$, el precio asociado es $\tilde{P}_{H}$ en $D$, y el sistema converge hacia el equilibrio estacionario $\left(\hat{P}_{H}, \hat{H}\right)$ a lo largo del propio lugar geométrico $\dot{P}_{H}=0$. En consecuencia, unas expectativas estáticas, al desatender las implicaciones derivadas de la nueva construcción de viviendas, dan lugar a un perfil más exagerado del precio del activo vivienda que su contrapartida con expectativas racionales.

\section{Efectos a corto y a largo plazo de diferentes políticas públicas}

El modelo esbozado en la sección anterior proporciona un marco de referencia con el que evaluar tanto las trayectorias temporales como la configuración a largo plazo derivadas de la introducción o la modificación de las variables consideradas exógenas, tanto fiscales como no fiscales. En ambos casos se plantea la distinción entre cambios permanentes y cambios transitorios, y si los agentes tienen expectativas racionales, entre cambios anticipados y cambios no anticipados.

Las dos distinciones en el párrafo anterior devienen cruciales para el análisis de los efectos capitalización resultantes tanto de la política pública como en general de las variaciones de las variables exógenas. Los efectos capitalización son consecuencia de que la construcción de viviendas nuevas requiere tiempo y está sujeta a costes de ajuste, lo que implica que, en un instante dado, los cambios no podrán tener efectos inmediatos sobre el stock de capital residencial, con lo que éstos se canalizarán exclusivamente a través de variaciones en los precios del stock de vivienda preexistente. En otras palabras, la inelasticidad de la oferta de servicios/stock de vivienda a corto plazo hará que los efectos de los cambios en los parámetros se canalicen a través de variaciones en los precios del stock de vivienda existente en un instante de tiempo dado. Nótese también que en tanto en cuanto el cambio en la política sea permanente, la configuración a largo plazo será la misma con independencia del carácter anticipado o no anticipado de aquélla. En las dos subsecciones siguientes se distingue entre dos grandes «grupos de políticas», según estas modifiquen las curvas $\dot{P}_{H}=0$ o $\dot{H}=0$ en la Figura 1. Esto permitirá clarificar en la sección 4 la distinción entre incentivos al ahorro e incentivos a la inversión en vivienda. 


\subsection{Políticas que afectan al lugar geométrico $\dot{P}_{H}=0$}

Comenzando por los efectos inducidos sobre el lugar geométrico $\dot{P}_{H}=0, \mathrm{y}$ restringiendo el análisis a cambios de carácter permanente, los efectos concretos dependerán del mecanismo de formación de expectativas, y, cuando éstas son racionales, de si el cambio es o no anticipado por los agentes económicos. La Figura 2 ilustra los resultados cuando el cambio de política es no anticipado. Tomando como punto de partida el equilibrio estacionario asociado al punto $A$, con unos valores $\bar{P}_{H}$ y $\bar{H}$, si el cambio de política da lugar a un desplazamiento permanente a la derecha del lugar geométrico $\dot{P}_{H}=0$, el nuevo estado estacionario estará caracterizado por unos valores $\hat{P}_{H}$ y $\hat{H}$ en $E$. Puesto que el stock de capital residencial existente en el instante en que se anuncia y se implementa la política es $\bar{H}$, con unas expectativas racionales el precio de la vivienda aumentará hasta $\overline{\bar{P}}_{H}$ en $C$ para colocarse sobre la línea $B B^{\prime}$ e iniciar la trayectoria de consecución del nuevo equilibrio a lo largo de $C E$. Alternativamente, si las expectativas son estáticas, el precio de la vivienda aumentará hasta $\tilde{P}_{H}$ en $D$, e irá disminuyendo paulatinamente hasta alcanzar el nuevo equilibrio. Con independencia del mecanismo de formación de expectativas, el cambio de política en consideración se capitalizará en precios incrementados del stock de capital residencial existente en el instante en que se introduce la política.

\section{GRÁFICO 2}

\section{EFECTOS DE UNA MODIFICACIÓN PERMANENTE DEL LUGAR GEOMÉTRICO $\dot{P}_{H}=0$, CAMBIO NO ANTICIPADO}

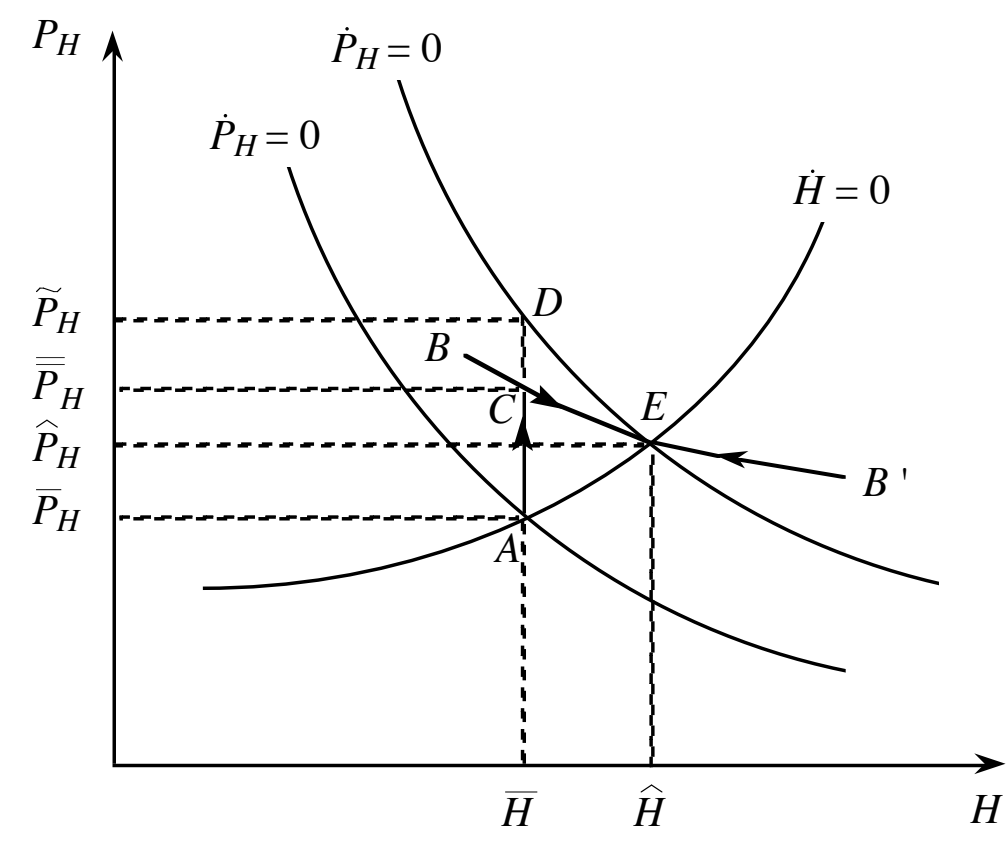


El Gráfico 3 muestra la situación en que las expectativas son racionales y el cambio es anticipado. Los agentes, en el instante 0 , anticipan que el cambio se instaurará en un futuro próximo, concretamente el instante $\tilde{\tilde{t}}$. De nuevo, los equilibrios estacionarios de partida y de llegada son $A$ y $E$, respectivamente. Obviamente, desde el instante 0 , en que se anuncia la política, hasta el $\tilde{\tilde{t}}$, en que se implementa, el sistema se regirá por las relaciones de comportamiento «antiguas», pues aún no se ha introducido el cambio. Solo será gobernado por las «nuevas» a partir de $\tilde{\tilde{t}}$, lo que significa que exactamente en ese instante el sistema debe hallarse sobre el lugar geométrico $B B^{\prime}$. La trayectoria del precio y del stock de vivienda es la representada por ACDE. El efecto capitalización, es decir, el incremento experimentado por el precio en el instante 0 , es menor que cuando la política era no anticipada, y en el instante $\tilde{\tilde{t}}$ el precio y el stock de vivienda son $\tilde{\tilde{P}}_{H}$ y $\tilde{\tilde{H}}$ en $D$. A partir de ahí, el sistema converge hacia el estado estacionario $E$.

\section{GRÁFICO 3}

EFECTOS DE UNA MODIFICACIÓN PERMANENTE DEL LUGAR

GEOMÉTRICO $\dot{P}_{H}=0$, CAMBIO ANTICIPADO

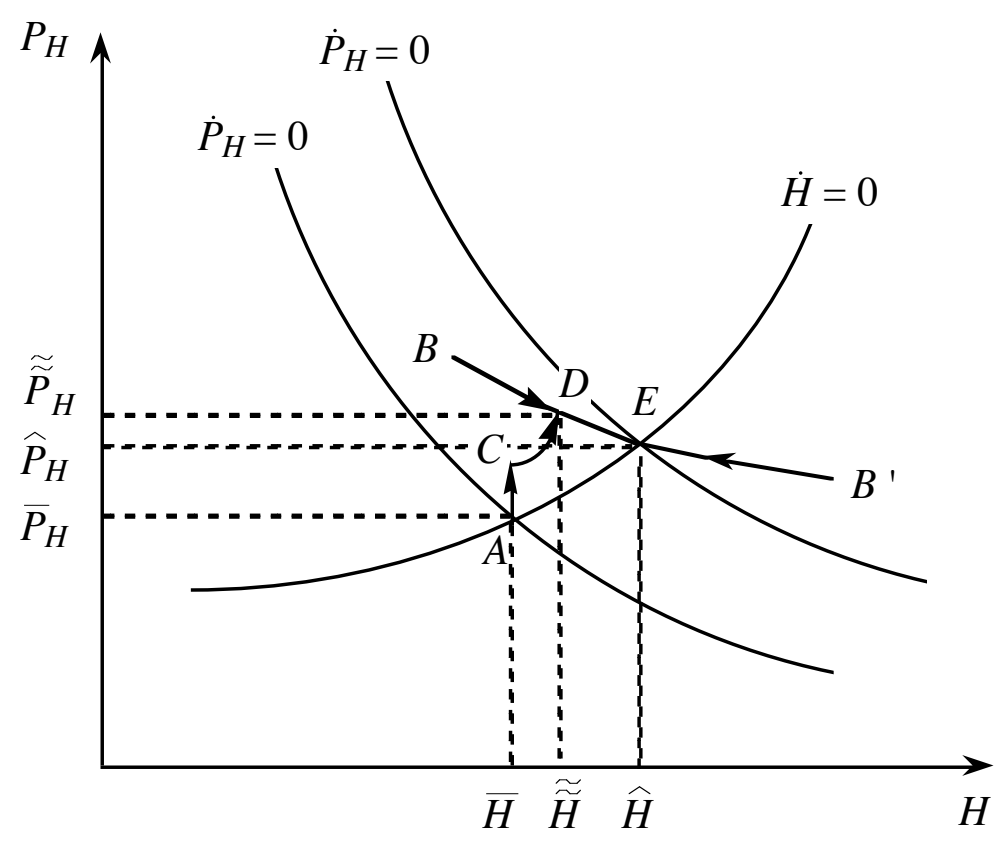




\subsection{Políticas que afectan al lugar geométrico $\dot{H}=0$}

Podemos ahora considerar los efectos de las políticas que actúan sobre el lugar geométrico $\dot{H}=0$, considerándolas de nuevo como políticas permanentes. Como en la subsección anterior, los efectos concretos de estas políticas dependerán de cómo formen sus expectativas los agentes, $\mathrm{y}$, en el caso en que éstas son racionales, del grado de anticipación. El Gráfico 4 permite obtener algunas indicaciones de los resultados con expectativas estáticas, así como con expectativas racionales cuando el cambio es no anticipado. Dado el equilibrio estacionario asociado al punto A, con unos valores $\bar{P}_{H}$ y $\bar{H}$, consideremos un cambio de política que da lugar a un desplazamiento permanente a la derecha del lugar geométrico $\dot{H}=0$. El nuevo estado estacionario es $E$, y sus valores de las variables son $\hat{P}_{H}$ y $\hat{H}$. El stock de capital residencial existente en el instante en que se anuncia y se implementa la política es $\bar{H}$, y en el caso de expectativas estáticas el precio de la vivienda no experimentará cambio alguno, manteniéndose en $\bar{P}_{H}$ e iniciando a partir de ese instante una disminución hasta el nuevo equilibrio, acompañada por un aumento del stock de capital residencial. Por el contrario, si las expectativas son racionales, el precio de la vivienda se reducirá instantáneamente hasta $\overline{\bar{P}}_{H}$ en $C$ sobre la línea $B B^{\prime}$, para a partir de ahí iniciar la trayectoria de consecución del nuevo equilibrio a lo largo de $C E$. Claramente, el cambio de política se capitalizará ahora en precios menores del stock de capital residencial existente en el instante en que se introduce la política.

\section{GRÁFICO 4 \\ EFECTOS DE UNA MODIFICACIÓN PERMANENTE DEL LUGAR GEOMÉTRICO $\dot{H}=0$, CAMBIO NO ANTICIPADO.}

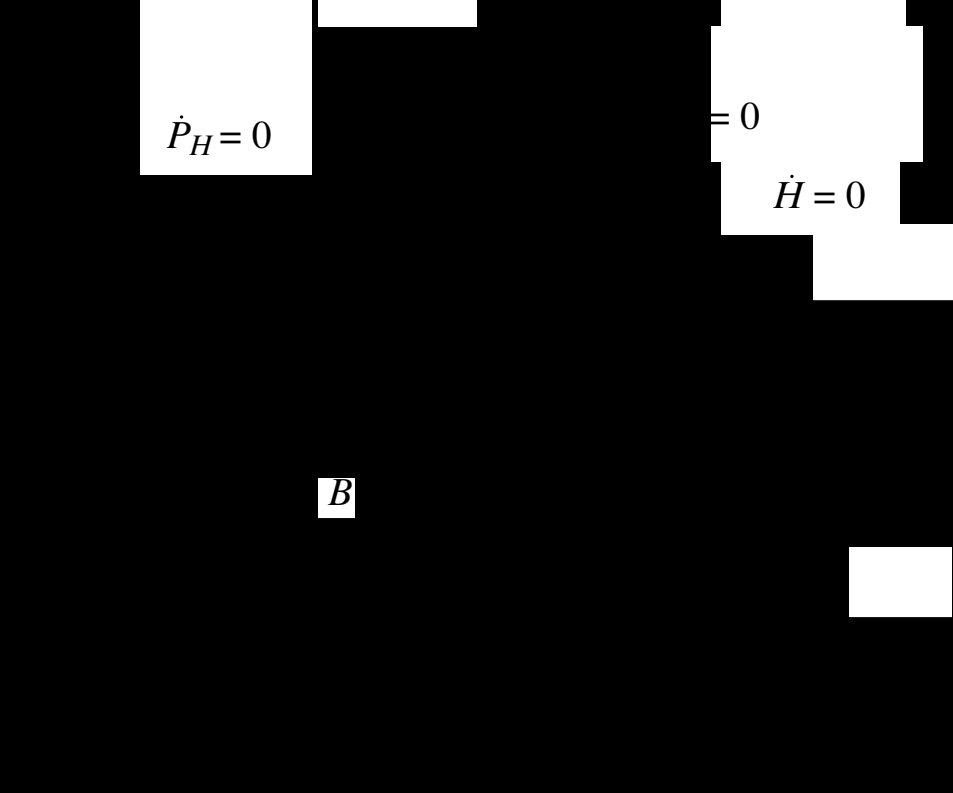


En el Gráfico 5 se ilustra la situación en que las expectativas son racionales y el cambio de política es anticipado. Como anteriormente, en el instante 0 los agentes anticipan que en el $\tilde{t}$ se implementará la nueva política. También al igual que antes, los equilibrios estacionarios de partida y de llegada son $A$ y $E$, respectivamente. Puesto que desde el instante 0 hasta el $\tilde{\tilde{t}}$ las relaciones de comportamiento son las «antiguas», y tan solo regirán las «nuevas» a partir de la implementación en $\tilde{\tilde{t}}$, el sistema debe hallarse sobre la línea $B B^{\prime}$ justo en ese instante. La trayectoria del precio y del stock de vivienda es la representada por ACDE. El efecto capitalización, es decir, la disminución experimentada por el precio de las viviendas existentes en el instante 0 , en que se anuncia el cambio, es menor que cuando la política era no anticipada. Lo que sucede ahora es que desde el instante 0 , de anuncio, al $\tilde{\tilde{t}}$, de implementación, se reduce el stock de vivienda, pues los agentes «retrasan» sus adquisiciones de vivienda hasta el cambio de política, y la depreciación actúa en el sentido de disminuir $H$. En el instante $\tilde{\tilde{t}}$ el precio y el stock de vivienda son $\tilde{\widetilde{P}}_{H}$ y $\tilde{H}$ en $D$, y a partir de ahí, el sistema converge hacia el estado estacionario $E$ con un stock de vivienda creciente y unos precios decrecientes.

\section{GRÁFICO 5}

\section{EFECTOS DE UNA MODIFICACIÓN PERMANENTE DEL LUGAR GEOMÉTRICO $\dot{H}=0$, CAMBIO ANTICIPADO}

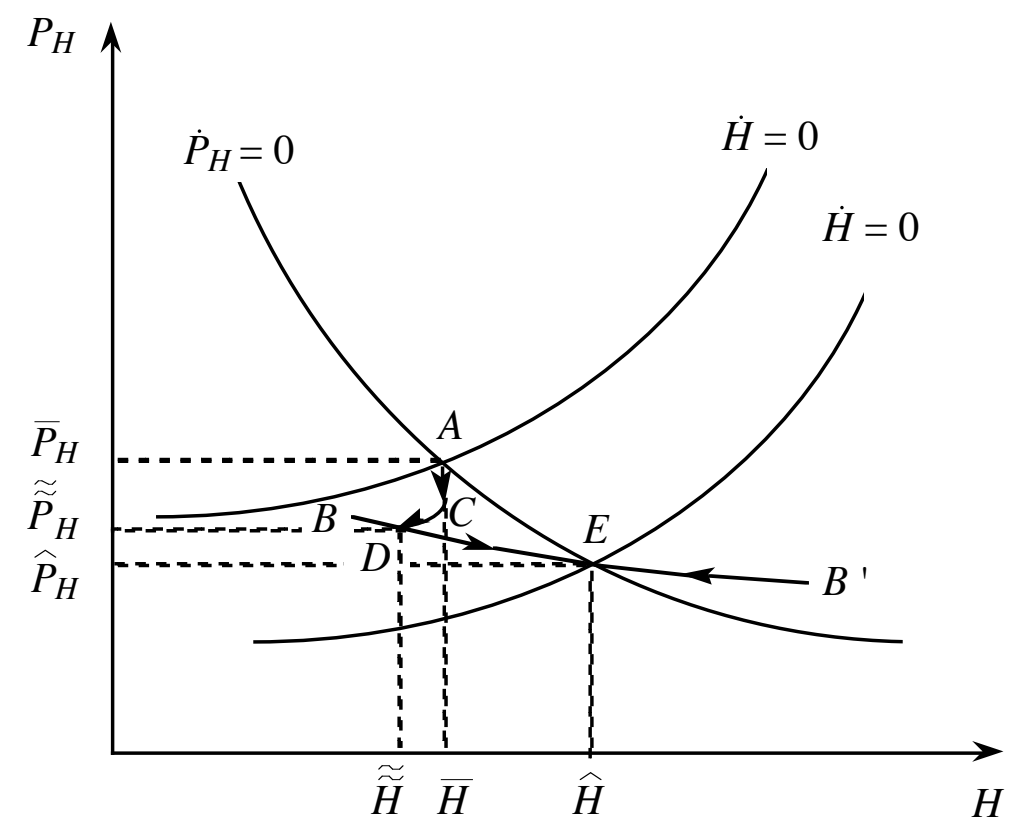


Para finalizar esta sección, debe insistirse en otro aspecto de cierta sutileza ligado a los efectos capitalización discutidos más arriba. Este hace referencia a en qué instante y qué agentes capturarán o sufrirán las ganancias o pérdidas de capital debidas a la revaloración, positiva o negativa, de los precios de la vivienda inducidos por los cambios exógenos. En el caso de expectativas estáticas y en el de racionales cuando el cambio es no anticipado, representados en las Figuras 2 y 4, aquellas ganancias o pérdidas tan solo se experimentarán en el instante en que se aplica la política, y por los agentes propietarios del stock de capital existente en ese instante. Tan solo estos reciben el «regalo o «castigo», y tras ese momento, es decir, tras la ganancia o pérdida de capital inicial, los propietarios de las viviendas siempre obtendrán el rendimiento nominal sobre su inversión en el activo vivienda que sea requerido a partir de la condición de arbitraje entre mantener su riqueza en forma de vivienda o en un activo financiero alternativo. Por su parte, si las expectativas son racionales pero el cambio se anticipa con anterioridad a su introducción, como en las Figuras 3 y 5, las ganancias o pérdidas tendrán lugar en el instante en que se anuncia la política, y serán experimentadas por los propietarios del stock existente. Cuando la política finalmente se introduce, los agentes ya se han ajustado a la nueva situación, y ya reciben el rendimiento nominal requerido, al igual que durante el periodo de transición desde el anuncio hasta la implementación.

\section{Incentivos al ahorro e incentivos a la inversión en vivienda}

A la vista de la discusión realizada en la sección anterior, resultan claras las diferencias en los efectos de las políticas que hacen desplazar los lugares geométricos $\dot{P}_{H}=0$ y $\dot{H}=0$. Esas diferencias son precisamente las que existen entre los denominados «incentivos al ahorro»y los «incentivos a la inversión», en nuestro caso en vivienda. Los incentivos al ahorro en vivienda mantienen invariado el precio relativo de las viviendas nuevas y pre-existentes, y pueden aplicarse a la adquisición de una unidad de vivienda con independencia de esta característica. Por su parte, los incentivos a la inversión en vivienda modifican el precio relativo de ambas, y tan solo pueden invocarse cuando la vivienda es de nueva creación. Por así decirlo, los primeros son «universales», en el sentido de que se pueden invocar tanto para una vivienda nueva como para una usada, mientras que los segundos son «selectivos», o, si se prefiere cargar las tintas, abiertamente «discriminatorios». Dicho de otra manera, los incentivos al ahorro positivos [negativos] desplazan a la derecha [izquierda] el lugar geométrico $\dot{P}_{H}=0$. Los incentivos a la inversión positivos [negativos] hacen desplazar el lugar geométrico $\dot{H}=0$ hacia la derecha [izquierda].

Algunos ejemplos de incentivo al ahorro en vivienda son los siguientes: (i) la introducción de una desgravación universal, bien sea en forma de deducibilidad de los intereses en el IRPF (el parámetro $b$ ), o una deducción en la cuota por pago de principal (es decir, tal que $c=s$ ); (ii) reducciones en los impuestos cuando éstos gravan al mismo tipo todas las transacciones de vivienda (es decir, un menor valor 
de $\tau_{I T P}=\tau_{I V A D}$ ); (iii) reducciones del tipo impositivo $\tau_{\triangle P A T}$ que grava las ganancias de capital vivienda; y (iv) una reducción, si así lo hubiera, del porcentaje de imputación de renta en especie a los efectos del IRPF (un parámetro no recogido en [1] pero que era positivo antes de la reforma del IRPF de 1998). Obsérvese que en todos estos casos la expresión [5] no se ve afectada. En efecto, cuando se trata del parámetro $b$ o del tipo impositivo $\tau_{\triangle P A T}$ porque ninguno de ellos aparece en esa expresión y cuando $c=s$ o $\tau_{I T P}=\tau_{I V A D}$ porque esos términos se cancelan en la condición de arbitraje [4] y no parecen por tanto en [5]. En términos de las Figuras 2 y 3 esto se traduce en un desplazamiento hacia la derecha y hacia arriba de la línea $\dot{P}_{H}=0$ y el mantenimiento de $\dot{H}=0$. Como ilustran esos diagramas, los efectos son un aumento del stock de capital residencial a largo plazo, de $\bar{H}$ a $\hat{H}$, pero también un aumento del precio real de las viviendas usadas, de $\bar{P}_{H}$ a $\hat{P}_{H}$. Adicionalmente, esto sucederá no solo en el estado estacionario, sino también a lo largo de la senda de consecución del equilibrio a largo plazo.

Los incentivos a la inversión, por el contrario, mantienen inalterada la expresión [2] (ó su contrapartida con expectativas estáticas) y tan solo modifican [5]. En la Figuras 4 y 5 , ello implica que lugar geométrico $\dot{H}=0$ se desplace a la derecha y hacia abajo, cuya interacción con un $\dot{P}_{H}=0$ invariado se manifiesta también en aumentos del stock de vivienda a largo plazo de $\bar{H}$ a $\hat{H}$, pero que ahora van acompañados por reducciones del precio real de las viviendas usadas, de $\bar{P}_{H}$ a $\hat{P}_{H}$. Ejemplos de incentivo a la inversión están constituidos por: (v) una reducción de $\tau_{\text {IVAD }}$, es decir, del tipo del impuesto que grava las transacciones de viviendas nuevas sin modificar su contrapartida $\tau_{I T P}$ sobre las viviendas usadas ni los porcentajes de desgravación en el IRPF $s$ y $c$ para ambas modalidades (ni, por supuesto, la deducción por intereses de capitales ajenos $b$ ); (vi) un aumento del tipo $s$ de subsidio fiscal en la adquisición de viviendas nuevas, todo ello sin modificar ni la deducción por adquisición de vivienda de segunda mano $c$ ni los impuestos que gravan las transacciones $\tau_{I V A D}$ y $\tau_{I T P}$ (y $\sin$ cambiar, de nuevo, la deducción por intereses $b$ ).

Al estar restringidos a las adquisiciones de capital residencial de nueva creación, los incentivos específicos para la vivienda nueva tratan de forma más favorable al capital nuevo que al capital existente. Y puesto que, por la condición de arbitraje [4], unidades de vivienda igualmente atractivas deben venderse al mismo precio, este tipo de política, al reducir el precio al consumidor de las viviendas nuevas, arrastrará hacia abajo al precio del capital residencial existente. Adicionalmente, esto es solo una parte de la historia, pues si bien los subsidios dirigidos a la vivienda nueva disminuyen el precio al productor de las viviendas existentes, generarán una mayor actividad constructora. El resultado será entonces un aumento en el stock de capital residencial. Puede obtenerse una intuición rápida de las consecuencias del funcionamiento de los incentivos a la inversión mediante el recurso al mercado de coches nuevos y coches usados, que comparten con la vivienda el hecho de ser sustitutos próximos. En particular, ¿cuál sería el efecto sobre el precio de los coches usados de la eliminación del impuesto de matriculación de los coches nuevos? ¡Sin duda, una disminución de los precios de los coches usados! Sea como fuere, la anterior 
discusión permite entonces afirmar que resulta posible mediante la introducción tanto de incentivos al ahorro como de incentivos a la inversión, conseguir los mismos efectos asignativos (un mayor stock de vivienda). Sin embargo, los efectos distributivos (sobre los precios reales de la vivienda preexistente, que constituyen el grueso de la riqueza inmobiliaria de las familias) son radicalmente diferentes.

\section{Una evaluación de la política impositiva dirigida a la vivienda en propiedad en España}

La discusión realizada en las secciones anteriores sugiere que si bien los subsidios a la vivienda son importantes, deben considerarse en un marco más amplio que contemple los demás componentes de la política impositiva dirigida a la vivienda. Sin embargo, con frecuencia se señala con un dedo acusador a las desgravaciones a la vivienda como uno de los elementos claves para explicar el comportamiento del mercado de vivienda en propiedad en España. Desde su introducción y hasta fechas bien recientes, el IRPF ha venido incorporado una variedad de disposiciones que otorgaban un tratamiento fiscal favorable a la vivienda habitada por su propietario. Estas preferencias fiscales se han plasmado en: (1) la posibilidad de deducir de la base o de la cuota del impuesto (con ciertos límites) los intereses de los capitales ajenos utilizados en la adquisición de la vivienda; (2) la posibilidad de invocar (también con ciertos límites) una deducción de la cuota tributaria por adquisición o rehabilitación de vivienda habitual; (3) un tratamiento ventajoso de las ganancias de capital asociadas a la venta de una unidad de vivienda, hasta el punto que en ocasiones el gravamen de aquéllas era nulo; y (4) cuando se sometían a gravamen las rentas imputadas del capital inmobiliario (antes de la reforma del IRPF de 1998), la consideración como base para la determinación de aquellas de unos valores catastrales muy alejados de sus contrapartidas de mercado.

El análisis realizado en las secciones anteriores sugiere que las preferencias fiscales (1) a (4) anteriores, en tanto en cuanto pueden aplicarse tanto a una vivienda de nueva creación como a una ya construida, podrían caracterizarse como una política de incentivo al ahorro en vivienda. Sin embargo, también es cierto que (2) podría restringirse a los casos en que se trata de una vivienda de nueva creación, y estaríamos entonces ante un genuino incentivo a la inversión en vivienda. Sin entrar en detalles que resultarían farragosos y desviarían la atención del mensaje principal, vale la pena hacer una evaluación de las preferencias (1) y (2). Desde 1980 hasta la reforma del IRPF de 1998, la deducibilidad en la base imponible del IRPF de los intereses de los capitales ajenos usados para adquirir una vivienda (que hacía que $b$ fuera igual al tipo marginal del contribuyente) se combinaba con una deducción de la cuota por los pagos de principal $c$. Puesto que además esta última era igual para las adquisiciones de viviendas nuevas y usadas, se cumplía que $c=s$. Claramente, ambas preferencias fiscales constituyen un incentivo al ahorro en vivienda. Una excepción está asociada al periodo 1985 a 1987, en que el porcentaje $c$ (igual al 15 por 100) de deducción de 
la cuota del IRPF por adquisición de vivienda usada se vio complementado por un valor $s$ (igual al 17 por 100) si era de nueva construcción (aunque no fuera habitual). Esto dio lugar a un efímero incentivo a la inversión. Tras la reforma fiscal de 1998 las condiciones se endurecieron ligeramente y los pagos por principal y por intereses se refundieron en una deducción de la cuota del IRPF (aplicable hasta una cuantía máxima), de manera que $b=c=s$, manteniendo por tanto un incentivo al ahorro en vivienda. A partir de 2013 ya no existen subsidios fiscales a la vivienda (aunque aquellos contribuyentes que adquirieron sus viviendas antes de esta fecha pueden seguir invocando la desgravación).

En cuanto a (3), es decir, el tratamiento preferencial de las ganancias de capital vivienda, los incrementos de patrimonio puestos de manifiesto con ocasión de la enajenación de la vivienda habitual no son sometidos a gravamen en caso de reinversión en la adquisición de otra unidad que constituye el domicilio habitual del contribuyente. Adicionalmente, la reforma del IRPF de 1998 introdujo la novedad de declarar exentas las ganancias de capital vivienda derivadas de la transmisión de la vivienda habitual por las personas mayores de sesenta y cinco años. Ambas consideraciones son frecuentemente usadas como argumento para considerar que $\tau_{\triangle P A T}$ es (aproximadamente) cero.

Los impuestos que gravan las transacciones de vivienda deben también tomarse en consideración para evaluar las características de la política impositiva dirigida a la vivienda. El IVA aplicable a las transacciones de viviendas de nueva creación ha venido siendo sistemáticamente mayor que el ITP que grava las compraventas de viviendas usadas. Teniendo en cuenta además el IAJD que gira sobre las primeras, el porcentaje $\tau_{I V A D}$ ha excedido y excede a su contrapartida $\tau_{I T P}$. Esto, unido al hecho de que $c=s$ en la condición de arbitraje [4], da lugar a una política de incentivo a la inversión negativo. Nótese que la presencia del IAJD que grava las transacciones de viviendas nuevas implica que este será el caso incluso si los tipos del IVA son iguales a los del ITP. Una excepción a lo anterior estuvo asociada al poco más de un año en que el IVA aplicable a las adquisiciones de viviendas nuevas fue un tipo superreducido (igual al 4 por 100) antes de volver a ser incrementado (al 10 por 100) en 2013.

En definitiva, puede afirmarse que el ordenamiento fiscal en nuestro país referido a la vivienda habitual en propiedad ha venido dando lugar a una política estructural de incentivo al ahorro positivo complementado con un incentivo a la inversión negativo. Tras la eliminación de las desgravaciones por vivienda en el IRPF, sin embargo, la situación puede caracterizarse como un incentivo al ahorro negativo (por la existencia del gravamen $\tau_{I T P}$ sobre las transacciones de viviendas preexistentes) combinado con el mantenimiento de un incentivo a la inversión negativo (derivado del hecho de que el impuesto $\tau_{I V A D}$ sobre las compraventas de viviendas nuevas excede a su contrapartida $\tau_{\text {ITP }}$ para las usadas). A la vista de la discusión de las secciones anteriores, resulta claro que la eliminación de las desgravaciones por pago de intereses y devolución de principal tendrá como efecto, tanto a largo plazo como durante los periodos transitorios, una reducción del precio real de la vivienda. Pero el resultado será también una disminución del stock de capital residencial. En 
efecto, interpretando en las Figuras 2 y 3 el punto $E$ como la situación de partida, el resultado a largo plazo (pero también a corto plazo y durante la transición entre los estados estacionarios $E$ y $A$ ) sería una reducción del precio real de la vivienda de $\hat{P}_{H}$ a $\bar{P}_{H}$, acompañada por una también disminución del stock de capital residencial de $\hat{H}$ a $\bar{H}$.

Si el objetivo a conseguir por parte del artífice de la política al eliminar las desgravaciones era hacer bajar los precios del stock de vivienda existente, puede decirse que el éxito de la medida es absoluto y completo. En otras palabras, como política estructural, la eliminación de los incentivos al ahorro a que eran equivalentes aquéllas se manifestará en menores precios de la vivienda. Esto equivale a afirmar que sus efectos prevalecerán con independencia de la situación subyacente en el mercado de vivienda, es decir, sean cuales fueren el comportamiento (en nivel y en evolución temporal) de la variable renta relevante para las decisiones de vivienda y las condiciones de acceso al crédito por parte de las familias.

Sin embargo, cabe también preguntarse por la posibilidad de que la reducción de la cantidad de vivienda no fuera, en realidad, uno de los objetivos perseguidos por el artífice de la política. Más aún, resulta tentador preguntarse si resultaría posible conseguir una reducción adicional en el precio de la vivienda con un menor efecto negativo sobre el stock. La discusión realizada más arriba sugiere que, de nuevo como política estructural, esto resulta posible complementando la eliminación del incentivo al ahorro a que equivalían las desgravaciones «universales» con la introducción de un incentivo genuino a la inversión. Si en las Figuras 4 y 5 el punto $A$ representa la situación en que ya no existen desgravaciones universales por vivienda (y por tanto, el precio $\bar{P}_{H}$ es ya inferior al existente en presencia de desgravaciones), la introducción de un incentivo a la inversión dará lugar a un nuevo equilibrio a largo plazo en $E$. En términos de efectos sobre los precios, tanto la eliminación del incentivo al ahorro como la introducción del incentivo a la inversión operan en la misma dirección (este último deprimiendo los precios hasta $\hat{P}_{H}$ ), de manera que los precios de la vivienda serían definitivamente menores que antes de la eliminación de las desgravaciones. Y el efecto final sobre el stock de vivienda dependerá de la fuerza relativa del efecto negativo de la supresión del incentivo al ahorro (que dio lugar a $\bar{H}$ ) y el efecto positivo de la introducción del incentivo a la inversión (que permite el aumento del stock hasta $\hat{H}$ ).

En suma, complementando la eliminación del incentivo al ahorro a que equivalían las desgravaciones a la vivienda en propiedad con la introducción de un incentivo a la inversión genuino, sería posible conseguir reducciones adicionales en el precio real de la vivienda con un efecto lateral menor en términos de reducción del stock de capital residencial. Más aún, con la elección adecuada de la constelación de parámetros fiscales (es decir, con el manejo adecuado de los lugares geométricos $\dot{P}_{H}=0$ y $\dot{H}=0$ en las figuras anteriores) resultaría posible mantener invariada cierta cantidad de stock de capital residencial que fuera juzgada deseable, pero con diferentes, y, en particular, menores, precios reales de la vivienda preexistente (en contraposición a la nueva). 
Tres comentarios emergen a la luz de las afirmaciones anteriores. El primero es que los efectos sobre el presupuesto público de los incentivos al ahorro y a la inversión en vivienda son radicalmente diferentes. Obviamente, no es lo mismo un subsidio fiscal que puede invocarse solo en la adquisición de las viviendas marginales (de nueva creación) o que resulta de aplicación para cualquier unidad de vivienda inframarginal (preexistente). Esta afirmación no por obvia debe dejar de enfatizarse en un momento como el actual para las arcas públicas.

El segundo hace referencia a la relación entre los incentivos a la inversión, la inversión residencial y los precios de las viviendas de nueva creación. Para fijar el argumento considérese la posibilidad con la que acaba el segundo párrafo anterior, es decir, un stock de vivienda invariado asociado a diferentes precios de la vivienda pre-existente. Puesto que ese stock no va a experimentar cambios, tampoco deberá variar la inversión residencial bruta asociada (que en un estado estacionario será a su vez igual a la inversión de reposición ligada a la depreciación del stock). La consecuencia es entonces que no habrá variaciones en el precio de las viviendas de nueva construcción. En otras palabras, a pesar de que el precio al productor de las viviendas usadas pueda ser diferente, el precio al productor de las viviendas nuevas sería exactamente el mismo. Este hecho ilustra una vez más la sutileza que esconde el funcionamiento de los incentivos a la inversión, en este caso en vivienda.

El último comentario relaciona la política impositiva con las transferencias intergeneracionales de renta y riqueza, así como con la dirección que pueden adoptar éstas. A lo largo de este trabajo el énfasis se ha colocado en los efectos de la política pública sobre los precios al productor de las viviendas pre-existentes. Podría, por el contrario, y sin apenas cambios, haberse centrado en los precios al productor de las viviendas nuevas. Para ello tan solo debería haberse usado la condición de arbitraje [4] y colocar en el eje vertical de las figuras anteriores $P_{H N}$ en vez de $P_{H}$. Sin embargo, son las viviendas usadas las que constituyen el grueso de la riqueza inmobiliaria de las familias. Y ésta pertenece a los estratos de más edad de la población. Por tanto, cuanto más altos sean los precios de estas viviendas, mayor será la cantidad de sus recursos de ciclo vital que los más jóvenes y las generaciones futuras deberán dedicar para adquirir sus viviendas, lo que dejará en sus manos menos recursos para ahorrar y consumir, con un efecto más que previsible sobre sus decisiones de fecundidad. Desde esta perspectiva, los efectos derivados de los periodos de boom inmobiliario y los incrementos asociados de los precios reales de la vivienda constituyen una transferencia de renta y riqueza de los segmentos más jóvenes de la población a los de más edad. Por tanto, poder conseguir reducciones en el precio de la vivienda sin por ello reducir el stock de la misma daría lugar a transferencias de renta en favor de las generaciones más jóvenes y las por nacer y en contra de las de más edad, propietarias de los activos inmobiliarios. Los incentivos a la inversión en vivienda emergen entonces como un poderoso instrumento al alcance del artífice de la política con el que intentar neutralizar los efectos renta intergeneracionales no deseados que puedan derivarse del funcionamiento del mercado de la vivienda. 


\section{Comentarios finales}

Las secciones anteriores han discutido una variedad de aspectos de la interrelación entre política de vivienda y política impositiva. El marco para el análisis ha sido un modelo agregado de vivienda, en su forma de tenencia en propiedad, que toma en consideración, por un lado, las decisiones de consumo-adquisición de serviciosstock de vivienda, y, por el otro, el comportamiento de la construcción residencial. Y se ha mostrado que el mecanismo de formación de expectativas respecto a la evolución futura de los precios reales de la vivienda, ya racionales, ya estáticas, juega un papel fundamental para la determinación de las trayectorias temporales del precio del activo vivienda y del stock de capital residencial.

El modelo proporciona un marco de referencia con el que evaluar tanto las trayectorias temporales como la configuración a largo plazo derivadas de la introducción o la modificación de las variables consideradas exógenas, tanto fiscales como no fiscales. En ambos casos se plantea la distinción entre cambios permanentes y cambios transitorios, y si los agentes tienen expectativas racionales, entre cambios anticipados y cambios no anticipados. Estas dos distinciones resultan fundamentales para la evaluación de los efectos capitalización resultantes tanto de la política pública como en general de las variaciones de las variables consideradas exógenas.

En base a ese modelo se han analizado las consecuencias de la distinción entre los «incentivos al ahorro»y los «incentivos a la inversión», en nuestro caso en vivienda. Los primeros son políticas universales que no distinguen entre las viviendas preexistentes y las de nueva creación, mientras que los segundos consisten en políticas selectivas dirigidas específicamente a las viviendas nuevas. Se ha argumentado que en el pasado el ordenamiento fiscal en España ha venido sido equivalente a la conjunción de un incentivo al ahorro positivo y un incentivo a la inversión negativo. Sin embargo, tras la reciente eliminación de las desgravaciones por adquisición de vivienda, la situación puede caracterizarse como un incentivo al ahorro negativo combinado con un incentivo a la inversión también negativo.

Finalmente, la discusión ha relacionado la política impositiva con las transferencias intergeneracionales de renta y riqueza derivadas del funcionamiento de los mercados de vivienda, así como con la dirección que pueden adoptar éstas. Los procesos que pueden resumirse en la expresión boom inmobiliario comportan una transferencia de renta de los segmentos más jóvenes de la población y las generaciones futuras a los de más edad, que ven cómo sus activos en forma de vivienda aumentan de precio. Desde luego, cuanto más altos sean los precios de la vivienda, mayor será la cantidad de sus recursos de ciclo vital que los más jóvenes y las generaciones futuras deberán dedicar para adquirir sus viviendas, lo que dejará en sus manos menos recursos para ahorrar, consumir, y, por qué no, tener hijos. Poder conseguir reducciones en el precio de la vivienda sin por ello reducir el stock de la misma tendría la ventaja añadida de dar lugar a transferencias de renta en dirección contraria. Los incentivos a la inversión en vivienda constituyen probablemente uno de los pocos instrumentos con los que conseguir esos efectos. 


\begin{abstract}
APÉNDICE
La contribución de referencia para el modelo del precio del activo vivienda desarrollado en las secciones 2 y 3 es Poterba (1984), y deben también mencionarse Topel y Rosen (1988), Mankiw y Weil (1989), Poterba (1991) y DiPasquale y Wheaton (1994). Un análisis pormenorizado de los fundamentos de este tipo de modelos, así como de los diagramas de fase y la (in)estabilidad de punto de silla del estado estacionario, puede encontrarse (en orden creciente de dificultad) en Begg (1982), Shreffin (1983), Romer (2012, cap. 9) y Dixon, Parmenter, Powell y Wilcoxen (1992).

Este tipo de modelos se ha mostrado extremadamente útil para la evaluación de reformas fiscales relacionadas con la vivienda en propiedad en distintos países (Asberg y Asbrink; 1994; Bruce y Holtz-Eakin, 1999) e incluso para aproximar el comportamiento de mercados de vivienda localizados (DiPasquale y Wheaton, 1996, cap. 10). También se ha usado para analizar diversas cuestiones relacionadas con la fiscalidad y la vivienda en España (López García, 1996, 1999, 2001, 2004, 2005 , 2010). En cuanto a la distinción entre incentivos al ahorro y a la inversión discutida en la sección 4, los efectos de estas políticas tanto sobre los precios de los bienes de capital (nuevos y usados) como sus consecuencias para la política fiscal en un contexto dinámico, han sido vigorosamente subrayados por Auerbach y Kotlikoff (1983, 1987a, 1987b, cap. 9) y Kotlikoff (1983, 1984).

En lo referido al modelo de determinación del precio del activo vivienda propiamente dicho, en el caso de que las expectativas son racionales, la expresión [2] en el texto principal describe una ecuación diferencial que gobierna la variación en el precio real de la vivienda ya construida en función de su precio, del stock de viviendas existentes, $\mathrm{y}$ de los valores de los parámetros fiscales $b, c, \tau_{\text {ITP }} \mathrm{y} \tau_{\triangle P A T}$ :

$$
\dot{P}_{H}=F\left(P_{H}, H ; b, c, \tau_{I T P}, \tau_{\triangle P A T}\right)
$$

Por su parte, la ecuación diferencial [5] que gobierna el comportamiento de la inversión residencial neta puede escribirse como:

$$
\dot{H}=G\left(P_{H}, H ; c, s, \tau_{I T P}, \tau_{\triangle I V A D}\right)
$$

donde los parámetros fiscales relevantes son $c, s, \tau_{I T P}$ y $\tau_{I V A D}$.

Con unas expectativas racionales, [A.1] y [A.2] constituyen un sistema dinámico que, dadas ciertas condiciones iniciales para el precio y el stock, describe las trayectorias temporales de $P_{H}$ y $H$ en función del tiempo, $t$, y un vector $z=\left(b, c, s, \tau_{I T P}, \tau_{I V A D}, \tau_{\triangle P A T}\right)$ de parámetros fiscales, es decir, $P_{H}=J(t, z)$ y $H=K(t, z)$. En un estado estacionario tanto el precio real de la vivienda como el stock de capital residencial no varían. En términos de la figura 1 esto tiene lugar cuando se cortan los lugares geométricos $\dot{P}_{H}=0$ y $\dot{H}=0$. El sistema dinámico exhibe (in)estabilidad de punto de silla, de manera.que el estado estacionario solo puede conseguirse a través del «brazo estable»
\end{abstract}


$P_{H}=M(H, z)$ representado como $B B^{\prime}$ en esa figura. Invirtiendo la trayectoria del stock en función del tiempo, $t=K^{-1}(H, z)$, y sustituyendo en su contrapartida del precio, este lugar geométrico puede caracterizarse como $P_{H}=J\left(K^{-1}(H, z), z\right)=M(H, z)$. Cualquier condición inicial que no se halle sobre el brazo estable dará lugar al alejamiento del equilibrio estacionario. De esta manera, dado un stock de capital residencial inicial, su precio como activo vivienda debe colocarse sobre el brazo estable, y converger así hacia el estado estacionario.

Alternativamente, si las expectativas son estáticas, [A.1] se convierte en $F\left(P_{H}, H ; b, c, \tau_{I T P}, \tau_{\triangle P A T}\right)=0$. Reescribiendo el precio como función del stock y de las variables exógenas, es decir, $P_{H}=N\left(H ; b, c, s, \tau_{I T P}, \tau_{\triangle P A T}\right)$, y sustituyendo en [A.2], el modelo puede resumirse en la ecuación diferencial

$$
\dot{H}=Q\left(H ; b, c, s, \tau_{I T P}, \tau_{I V A D}, \tau_{\triangle P A T}\right)
$$

que proporciona la evolución temporal del stock de vivienda dada una condición inicial y el conjunto de parámetros fiscales. Puesto que ahora no se esperan cambios en el precio de las viviendas, dada cierta condición inicial para el stock, el precio asociado es el resultado de computar $P_{H}=N\left(H ; b, c, \tau_{I T P}, \tau_{\triangle P A T}\right)$, y el sistema converge hacia el equilibrio estacionario a lo largo del lugar geométrico $\dot{P}_{H}=0$ en la Figura 1. 


\section{Referencias bibliográficas}

[1] ASBERG, P. y ASBRINK, S. (1994). «Capitalisation Effects in the Market for OwnerOccupied Housing-A Dynamic Approach», Tax Reform Evaluation Report No. 2, National Institute of Economic Research, Estocolmo.

[2] AUERBACH, A. J. y KOTLIKOFF, L. J. (1983). «Investment versus Savings Incentives: the Size of the Bang for the Buck and the Potential for Self-Financing Business Tax Cuts». En L.H. Meyer (ed.), The Economic Consequences of Government Deficits, Kluwer-Nijhoff, 121-149.

[3] AUERBACH, A. J. y KOTLIKOFF, L. J. (1987a). «Evaluating Fiscal Policy with a Dynamic Simulation Model». American Economic Review, 77, 49-55.

[4] AUERBACH, A. J. y KOTLIKOFF, L. J. (1987b). Dynamic Fiscal Policy, Cambridge University Press, Cambridge.

[5] BEGG, D. K. H. (1982). The Rational Expectations Revolution in Macroeconomics, Oxford: Philip Alan.

[6] BRUCE, D. y HOLTZ-EAKIN, D. (1999). «Fundamental Tax Reform and Residential Housing». Journal of Housing Economics, 8, 249-271.

[7] DIPASQUALE, D. y WHEATON, W. C. (1994). «Housing Market Dynamics and the Future of Housing Prices». Journal of Urban Economics, 35, 1-27.

[8] DIPASQUALE, D. y WHEATON, W. C. (1996). Urban Economics and Real Estate Markets, Englewood Cliffs: Prentice-Hall.

[9] DIXON, P.B.; PARMENTER, B. R.; POWELL, A. A. y WILCOXEN, P. L. (1992). Notes and Problems in Applied General Equilibrium Economics, Amsterdam: North Holland.

[10] KOTLIKOFF, L. J. (1983). «National Savings and Economic Policy: The Efficacy of Investment vs. Savings Incentives». American Economic Review, 73, 82-87.

[11] KOTLIKOFF, L. J. (1984). «Taxation and Savings: A Neoclassical Perspective». Journal of Economic Literature, vol. 22, 1576-1629.

[12] LÓPEZ GARCÍA, M. A. (1996), «Precios de la vivienda e incentivos fiscales a la vivienda en propiedad en España», Revista de Economía Aplicada, Vol. 4, pp. 37-74.

[13] LÓPEZ GARCÍA, M. A. (1999). «Efectos de la reforma del IRPF sobre la vivienda». Revista de Economía Aplicada, 7, 95-120.

[14] LÓPEZ GARCÍA, M. A. (2001). Política impositiva, precios y stock de vivienda, Colección Estudios de Hacienda Pública, Instituto de Estudios Fiscales, Ministerio de Hacienda, Madrid.

[15] LÓPEZ GARCÍA, M. A. (2004). «Housing, Prices and Tax Policy in Spain», Spanish Economic Review, 6, 29-52.

[16] LÓPEZ GARCÍA, M. A. (2005). «La vivienda y la reforma fiscal de 1998: Un ejercicio de simulación». Hacienda Pública Española. Revista de Economía Pública, 175, 123 147.

[17] LÓPEZ GARCÍA, M. A. (2010). «La propuesta de reforma estructural del mercado de vivienda de FEDEA: una evaluación». Revista de Economía Aplicada, 52 (18), 153 175 .

[18] MANKIW, N. G. y WEIL, D. N. (1989). «The Baby Boom, the Baby Bust, and the Housing Market». Regional Science and Urban Economics, 19, 235-258. 
[19] POTERBA, J. M. (1984). «Tax Subsidies to Owner-Occupied Housing: An AssetMarket Approach». Quarterly Journal of Economics, 99, 729-752.

[20] POTERBA, J. M. (1991). «House Price Dynamics: The Role of Tax Policy and Demography». Brookings Papers on Economic Activity, 2, 143-183.

[21] ROMER, D. (2012). Advanced Macroeconomics, 4. . ed., McGraw-Hill, Nueva York.

[22] SHEFFRIN, S. M. (1983). Rational Expectations, Cambridge: Cambridge University Press.

[23] TOPEL, R. y Rosen, S. (1988). «Housing Investment in the United States». Journal of Political Economy, 96, 718-740. 
